\title{
DORSA HABENTES CONTRA POPULUM. UN APUNTE SOBRE FRONTERAS ÉTNICAS, RELIGIOSAS Y SOCIALES EN LAS FILIPINAS DEL SIGLO XVIII
}

\author{
Luis Ángel Sánchez Gómez \\ Universidad Complutense de Madrid
}

\begin{abstract}
RESUMEN: En el presente artículo se estudia un manuscrito inédito redactado por un fraile dominico español, párroco en una población rural filipina en 1760, en el que se describen en muy malos versos los rasgos presuntamente característicos de las tierras y las gentes del archipiélago filipino. Su autor denigra e insulta de forma reiterada a los nativos, tanto a hombres como a mujeres, construyendo un discurso no sólo racial sino decididamente racista. Tras contextualizar al personaje y a la Orden de Predicadores en la historia colonial filipina, comentamos el texto y presentamos algunas ideas que pueden resultar útiles para valorar la relevancia de la acción misional en Filipinas durante los siglos XVIII y XIX.
\end{abstract}

Palabras clave:

ABSTRACT: In the present article we study an unpublished manuscript written by a Spanish Dominican friar, parish priest in a Philippine village in 1760, in which the author describes in very bad verses the hypothetical characteristics of the lands and the peoples of the Philippines. The friar denigrates and insults repeatedly the natives, men and women, and constructs a not only racial but decisively racist discourse. After setting in a context the friar and the Dominican Order in the Philippine colonial history, we comment on the text and we present some ideas that can be useful to value the meaning of the missionary action in the Philippines during the 18th and the 19th centuries.

Keywords:

Nadie podrá ponerlo en duda: las coplas del dominico Fr. José de Azcárate que vamos a comentar no ofrecen, en cuanto que presunta obra poética, el menor interés técnico o artístico; su factura puede calificarse sin ambages como 
pésima. Es justo, por tanto, que su autor sea un completo desconocido; tampoco corremos muchos riesgos si afirmamos que nunca será citado en los libros de historia de la literatura española. Pese a todo, esos malos versos tienen algún interés, un interés que se vincula no con el ámbito de la literatura sino con el de la historiografía filipinista.

Las coplas del dominico Fr. José Azcárate están recogidas en un volumen que reúne varios manuscritos y un folleto impreso, todos ellos de temática filipinista, correspondientes al siglo XVIII y a la primera mitad del XIX, aunque hay uno más del XVII. Curiosamente, el primer escrito de este compendio (ff. 1-46) es una copia de la conocida "Carta que Fr. Gaspar de S. Agustín, Religioso del orden de Agustinos calzados, escribió a un amigo suyo que desde España le preguntó el natural y genio de los Yndios naturales de Filipinas", fechada en Manila, a 8 de junio de $1720^{2}$, de sesgo político y racial similar a los versos del dominico. La carta tuvo cierta relevancia en el contexto político de las décadas finales de dominación española en Filipinas, ya que no pocas de las afirmaciones denigrantes, o sencillamente racistas, recogidas por el agustino en su escrito -que nunca publiCó $^{3}$ - fueron reiteradamente citadas durante el último tercio del siglo XIX por los ilustrados ${ }^{4}$ filipinos como muestra del despotismo, la soberbia y el racismo de los

1. Mss. 7.861 [Miscelánea sobre las Islas de [sic] Filipinas], ff. 53-57. Biblioteca Nacional, Madrid.

2. El manuscrito citado dice 1725. Sin embargo, la fecha correcta es 1720. Fr. Gaspar había fallecido a principios de agosto de 1724 .

3. Fueron dos jesuitas contemporáneos de Fr. Gaspar, los PP. Pedro Murillo Velarde y Juan José Delgado, quienes inicialmente dieron a conocer parte de los contenidos de la carta en varias de sus obras. El primero compartía en buen medida las opiniones del agustino sobre los filipinos; el segundo, no. Sobre los avatares de la famosa carta, aún siguen siendo útiles los comentarios que incluye el P. Gregorio de Santiago Vela en su Ensayo de una Biblioteca IberoAmericana de la Orden de San Agustín. Vol. VII. S-T. [San Lorenzo de] El Escorial, 1925, pp. 114-116. Al margen de las negativas valoraciones que hace el autor sobre el uso que de la carta hicieron los ilustrados filipinos, sus indicaciones sobre las distintas copias de este manuscrito son interesantes. El P. Santiago se refiere también en esas mismas páginas a las coplas del P. Azcárate, asegurando que este escrito "acompaña generalmente a la carta [de Fr. Gaspar], como lo hemos visto en numerosas copias" (p. 115); sin embargo, no concreta en cuáles. Únicamente anota que la carta y las coplas se incluyen en el manuscrito de la Biblioteca Nacional de signatura mss. 12.976. Hemos comprobado que, efectivamente, dicho manuscrito contiene el texto del P. San Agustín, pero no el del P. Azcárate. Según el Inventario General de Manuscritos de la Biblioteca Nacional, el único ejemplar en el que aparecen encuadernados conjuntamente ambos escritos es el de signatura mss. 7.861, el que hemos consultado para la trascripción de las coplas. Una revisión completa de los índices del citado inventario nos permite afirmar que no se encuentra ninguna otra copia de las coplas entre los manuscritos de esa biblioteca. Desconocemos, por tanto, a qué otras copias se refiere el P. Santiago Vela.

4. Con esta denominación se conoce a los nativos, y también a los mestizos de chino y a los mestizos de español, de elevado estatus socioeconómico (y muchos de ellos universitarios) que se oponen al preponderante papel que ejercen los religiosos y reivindican la introducción de reformas administrativas y políticas en el archipiélago. En los años finales de la presencia española, algunos ilustrados asumen posiciones decididamente independentistas. 
frailes españoles, actitudes todas ellas materializadas en el más absoluto y despótico dominio del cuerpo, la mente y el alma del "indio"s. No obstante, pese a la parcial coincidencia temática existente entre las coplas y la carta, el volumen que las recoge no puede considerarse una compilación de escritos religiosos de corte racial o, simplemente, racista, elaborada bien para apoyar las tesis de los frailes o bien para denunciarlas. Aunque se incluyen unos pocos versos más de orientación similar, los restantes escritos tienen que ver con cuestiones diversas vinculadas con la expansión político-militar y misional en el archipiélago.

Ya hemos adelantado algo sobre la orientación de las coplas pero, antes de adentrarnos en su comentario, conviene decir algo sobre su autor y sobre la labor desarrollada por sus hermanos de la Orden de Predicadores en Filipinas.

De Fr. José Azcárate conocemos poco, pero lo suficiente para contextualizar al personaje en el ámbito territorial y misional de las Filipinas de mediados del siglo XVIII. Él mismo nos informa de que es un fraile dominico de origen vizcaíno y de que en 1760 está al frente de la parroquia de Paniqui ${ }^{6}$. Esta población había sido "recibida" por los dominicos en 1686 y pertenecía a la provincia de Pangasinán ${ }^{7}$, en la zona central de Luzón; más tarde, y hasta la actualidad, pasaría a formar parte de la nueva provincia de Tarlac. ${ }^{8}$. Aunque no se puede afirmar que el P. Azcárate dejara huella literaria (ni historiográfica) en suelo filipino, tampoco fue un simple párroco rural. No es citado en ninguna de las historias antiguas que documentan la obra de la Orden de Predicadores en Filipinas; no se le menciona en el espléndido volumen sobre Los Dominicos en el Extremo Oriente editado en $1916^{\circ}$, ni en el amplísimo listado de frailes que se recoge en

5. La voz "indio", o "indio filipino", es utilizada durante toda la etapa colonial para nombrar a los nativos de Filipinas cristianizados, es decir, a todos aquellos que no son "negritos", "igorrotes" o "moros". El término "filipino" solía identificar al español nacido en las islas, al "español filipino". A partir de ahora, y al margen de cualquier consideración peyorativa, utilizaremos la voz "indio" sin entrecomillar.

6. Debemos recordar que fue Pío $\vee$ (un dominico) quien hizo posible, mediante una bula promulgada en 1567, la creación de la figura del fraile-párroco en los territorios ultramarinos de España, permitiéndoles ejercer una actividad parroquial regularizada a pesar de la prohibición que al respecto se fija en el concilio de Trento. Precisamente las disputas y los enfrentamientos de los frailes (y sus provinciales) con las autoridades eclesiásticas seculares, cuya autoridad estaban obligados a acatar, estuvieron a la orden del día en Filipinas durante todo el periodo de dominio colonial español.

7. Hemos optado por emplear la tilde en los topónimos que usualmente se pronuncian en castellano con acento prosódico en la última sílaba, como ocurre con Pangasinán, Luzón o Cagayán.

8. La provincia de Tarlac posee diecisiete "municipalidades" (entre ellas Paniqui) y una ciudad (Tarlac City, la capital), y confina con las de Pangasinán (al Norte), Zambales (al Oeste), Pampanga (al Sur) y Nueva Écija (al Este).

9. Los Dominicos en el Extremo Oriente. Provincia del Santísimo Rosario de Filipinas. Relaciones publicadas con motivo del séptimo centenario de la confirmación de la Sagrada Orden de predicadores. Barcelona, 1916. 
el índice onomástico del voluminoso libro de Fr. Pablo Fernández ${ }^{10}$ (1958). Por supuesto, tampoco hemos encontrado referencia alguna al P. Azcárate, ni a sus coplas, en la reciente historiografía sobre la expansión misional dominicana en Filipinas. Sin embargo, sí aparece reseñado en la completísima compilación que publicara, en 1895, el P. Hilario María Ocio" (que cita a todos los dominicos enviados a Extremo Oriente), reseña que amplía con unos muy pocos datos más el también dominico Fr. Eladio Neira, en su actualización del compendio del P. Ocio publicada, en dos volúmenes, en el año $2000^{12}$. Veamos lo que ambos religiosos nos dicen sobre nuestro protagonista.

El P. José de Azcárate nace hacia 1725 en Ermua (Vizcaya). Ingresa en la Orden de Predicadores, en el convento de Santo Domingo de Osuna, alrededor de 1744. Parte hacia Nueva España en marzo de 1751 con la misión trigésimo quinta de la orden, compuesta por treinta y siete religiosos, y pasa un tiempo destinado en el Hospicio de San Jacinto de México. Ni el P. Ocio ni el P. Neira concretan en realidad cuándo toca tierra filipina, aunque puede que lo hiciera efectivamente con el grueso de la misión citada, que sale de Acapulco en abril de 1752 y llega a Manila en agosto del mismo año. Destinado a la provincia de Pangasinán, es vicario de Salasa (1757-1759), Malasiqui (1759-1763) y Paniqui (1763-1765). Éstos son los años que indica el P. Ocio y repite el P. Neira; sin embargo, ya hemos anotado que el P. Azcárate firma sus coplas en Paniqui en 1760 , por lo que muy probablemente las fechas no sean del todo correctas. Trasladado a Manila, preside el Hospital de San Gabriel y es "Procurador general de la provincia en Filipinas y del Beaterio de Santa Catalina [de Siena]" (17651777) ${ }^{13}$. En 1777 es nombrado párroco de Cavite, pero renuncia en enero de

10. Dominicos donde nace el sol. Historia de la provincia del Santísimo Rosario de Filipinas de la Orden de Predicadores. Barcelona, 1958.

11. Compendio de la reseña biográfica de los religiosos de la Provincia del Santísimo Rosario de Filipinas. Desde su fundación hasta nuestros días. Por el autor de la misma. Manila, 1895. La breve biografía del P. Azcárate aparece en las páginas 414 y 415.

12. Son dos volúmenes: Misioneros dominicos en el Extremo Oriente, 1587-1835. Manila, 2000 y Misioneros dominicos en el Extremo Oriente, 1836-1940. Manila, 2000. En el primero aparecen como autores los PP. Ocio y Neira (por este orden); en el segundo, los PP. Neira, Ocio y Gregorio Arnáiz (este último amplió la obra del P. Ocio con información hasta el año de 1945, aunque no llegó a publicarla). La biografía del P. Azcárate se incluye en la página 347 del primer volumen.

13. El Hospital de San Gabriel fue construido por los dominicos en 1588 en el arrabal del Parián, para atender a los chinos conversos. Destruido a finales del siglo XVI, se traslada (como la mayor parte de los sangleyes cristianos) al barrio manilense de Binondo, donde abre de nuevo sus puertas en 1599. Fue una institución importante en la ciudad. Se cerró, al parecer, en 1774 , supuestamente (según el P. Neira) como castigo por el apoyo de los chinos a la invasión inglesa de Manila en 1762. Según esto, la presidencia del P. Azcárate (que no pudo extenderse hasta 1777) debió de desarrollarse en un contexto bastante turbulento. Por lo que se refiere al beaterio, fue una institución benéfico-docente para niñas y jóvenes fundada en 1696 por monjas dominicas. Su heredero es, desde 1959, el actual Siena College, de la Congregación de las Hermanas Dominicas de Santa Catalina de Siena, en Quezon City. 
1778, tras ser elegido sustituto del vicario-procurador de San Jacinto de México, donde ya estuviera destinado tras su llegada a tierras americanas; sin embargo, no llega a tomar posesión del cargo, pues fallece el 31 de marzo de ese mismo año. Además de los destinos citados, fue notario del Santo Oficio en Manila y secretario de los definitorios ${ }^{14}$ de tres Capítulos provinciales dominicos consecutivos $(1765,1769$ y 1773), lo que, según el P. Neira, "habla muy alto de sus cualidades personales y de la estima [de] que gozaba en la Provincia".

Aunque más tarde retomaremos algunos aspectos de la biografía del P. Azcárate, es evidente que no estamos ante un simple vicario rural (aunque lo fuera durante buena parte de su vida), pero tampoco ante un personaje de primera fila en la historia de la Orden de Predicadores. El papel desempeñado por los dominicos en la historia y en el presente de Filipinas es mucho más significativo de lo que podría dar a entender la figura del fraile vizcaíno, y esto es algo que los mismos religiosos se encargan de reivindicar y exaltar desde fecha temprana. En efecto, al igual que hacen todas las órdenes católicas importantes, la de predicadores asume pronto y con entusiasmo la tarea de historiar su propia actividad misional, en este caso su actividad misional en Filipinas y el Extremo Oriente, siempre desde una perspectiva marcadamente hagiográfica o, simplemente, autocomplaciente, aunque en ningún caso exenta de interés. Entre las obras antiguas, pueden destacarse las historias de la provincia del Santísimo Rosario ${ }^{15}$ (de Filipinas, China, Formosa, Japón y Tonkín' ${ }^{16}$ de Fr. Diego Francisco Aduarte (1640), Fr. Baltasar de Santa Cruz (1693), Fr. Vicente de Salazar (1742) y Fr. Domingo Collantes (de 1783) y la extensa Historia de los PP. Dominicos en las Islas Filipinas y en Extremo Oriente (en seis volúmenes) iniciada por el P. Juan Ferrando y ampliada por Fr. Joaquín Fonseca (1870-1872). En fechas mucho más recientes ha continuado la tradición historiográfica dominicana, aunque con una marcada orientación hacia el estudio de la tarea desarrollada en tierras americanas, al menos por lo que se refiere a las investigaciones impulsadas desde España ${ }^{17}$. No obstante, existe también una muy importante tradición de estudios sobre el Extremo Oriente y

14. Según el DRAE: "Cuerpo que, con el general o provincial de una orden, componen para regirla los religiosos definidores generales o provinciales". También identifica a la junta o congregación que celebran los propios definidores.

15. Ésta es la denominación utilizada en la mayor parte de las obras de época moderna citadas para hacer referencia a la estructura territorial y administrativa de expansión misional dominicana en Extremo Oriente. No obstante, el nombre "oficial" es Provincia de Nuestra Señora del Rosario.

16. Tonkín, Tunkín, Tun-kin o Tung-kin son denominaciones antiguas del actual Vietnam, concretamente de sus territorios más septentrionales.

17. Con el título genérico de "Los dominicos y el Nuevo Mundo" se han celebrado congresos internacionales en Sevilla (1987), Salamanca (1989), Granada (1990), Bogotá (1993), Querétaro (1995) y Bayamón (Puerto Rico, 1998). De todos ellos se han publicado las correspondientes actas. Los trabajos presentados sobre Filipinas en estos congresos son muy escasos. Otra obra dominicano-americanista que se puede citar es la redactada por M. A. Medina, OP: Los dominicos en América. Presencia y actuación de los dominicos en la América colonial española de los siglos XVI-XIX. Madrid, 1992. 
Filipinas, que ha visto la luz en la serie denominada Orientalia Dominicana, publicada en diversas ciudades de España, Filipinas y Japón, e iniciada en conmemoración del cuarto centenario de la creación de la Provincia de Nuestra Señora del Rosario ${ }^{18}$. Precisamente algunos de los trabajos más detallados sobre la presencia dominicana en Filipinas pertenecen a la citada serie. Nos referimos a sendas obras colectivas editadas por Fr. Jesús González Valles ${ }^{19}$ y Fr. Manuel González Pola ${ }^{20}$, y a la citada edición corregida y actualizada que ha hecho el P. Eladio Neira del Compendio del P. Ocio. Insistimos en que no pocas de estas obras ofrecen interesante información ${ }^{21}$, aunque en realidad la mayoría presenta un carácter muy marcadamente hagiográfico.

Al margen de la visión que los dominicos nos ofrecen sobre sí mismos, y aunque no tendría sentido entrar ahora en valoraciones ideológicas y fácticas sobre el desarrollo histórico de la Orden de Predicadores, lo que resulta evidente es que su relevancia y significado van mucho más allá de su especialísima y siempre citada vinculación con la Inquisición ${ }^{22}$, algo que se demuestra con mencionar sólo los nombres de tres frailes dominicos: Tomás de Aquino, Bartolomé de las Casas y Francisco de Vitoria. Por lo que se refiere al archipiélago filipino, allí desarrolla su labor un dominico tan destacado como Fr. Domingo de Salazar, primer obispo (los siguientes serán ya arzobispos) de Manila y responsable de la convocatoria del famoso primer sínodo (aunque técnicamente no fuera tal) de Manila de 1582; y también son dominicos otros seis arzobispos de Manila, entre ellos los dos últimos de la etapa española: Fr. Pedro Payo (1876-1889), personaje que detenta un enorme poder político en el archipiéla-

18. No es fácil disponer de un listado completo de la colección (que no presenta un formato homogéneo), cuyo último título parece haber sido editado en el año 2000. Curiosamente, el catálogo electrónico de la dominicana Universidad de Santo Tomás (en Manila) sólo cita seis títulos de la serie. Un listado más amplio se obtiene a través del catálogo de la Red de Bibliotecas Universitarias Españolas (REBIUN, http://rebiun.crue.org). También se citan muchas de las obras, pero no todas, en el libro Witnesses of the Faith in the Orient, accesible a través de la página web http://www.op-stjoseph.org/dom-images/pdf-files/witnesses.pdf.

19. Cuatro siglos de evangelización (1587-1987). Rutas misioneras de los dominicos de la Provincia de Nuestra Señora del Rosario. Madrid, 1987.

20. Dominicos españoles en el Extremo Oriente. IV Centenario. Madrid, 1988. También pueden citarse varios artículos del mismo autor: "Los dominicos en Filipinas", Actas del I Congreso Internacional sobre los dominicos y el Nuevo Mundo. Sevilla: 21-25 de abril de 1987. Madrid, 1988, pp. 255-290; "Evangelización de los dominicos en Filipinas (siglo XVII)", Actas del III Congreso Internacional sobre los dominicos y el Nuevo Mundo. Granada, 10-14 de septiembre de 1990. Madrid, 1991, pp. 465-493; "Evangelización de los dominicos en Filipinas en los siglos XVI y XVII". Studium 32 (2) (1992), pp. 351-396.

21. Desearía destacar la edición bilingüe (en español e inglés) hecha por William Henry Scott de la "Noticia de los Ynfieles Ygorrotes", escrita por el dominico Fr. Francisco Antolín en 1789: Notices of the pagan Igorots in the interior of the Island of Manila. Manila, 1988. Es el quinto título de la serie Orientalia Dominicana, subserie Filipinas.

22. De la que fuera víctima otro gran dominico, Giordano Bruno. 
go, y Fr. Bernardino Nozaleda (1889-1902), que ejerce los últimos años de su mandato ya bajo el dominio norteamericano. Pero no es necesario extendernos más en preliminares. Centrémonos ya en el contenido de las coplas.

Es casi inevitable que el fraile comience su torpe versificación presentando a las islas Filipinas como el "fin del mundo" (v. 2). La enorme distancia que las separa de la metrópoli, e incluso del que fuera principal territorio de intermediación entre ambas (Nueva España), hace que sea la posesión ultramarina más excéntrica del imperio español. De hecho, será siempre (y no sólo por razones geográficas) "la colonia más peculiar"23, tanto antes como después de la pérdida del imperio americano. Llegar hasta ella implica atravesar una frontera con mayúsculas, y no sólo geográfica. Como el dominico no concede tregua alguna, su pluma viperina se abalanza de forma casi inmediata sobre las tierras y las gentes de las islas. Que denomine a Filipinas "segunda Sierra Morena" (v. 16) es tanto como llamar ladrones a todos sus habitantes, de quienes a renglón seguido se mofa por el tono oscuro de su piel, su presunto mal olor corporal y su escasa religiosidad. La referencia al color de la piel es el tópico racista por excelencia, y poco hay que comentar al respecto. Sin embargo, citar en 1760 a la ciudad de Madrid como prototipo de espacio suministrador de agradables fragancias parece una broma de mal gusto (v. 19); claro que, aún es más disparatado recurrir a Ana Bolena como prototipo de mártir al que debieran ajustarse los filipinos (v. 20), y no porque la desgraciada segunda esposa de Enrique VIII careciera de valores morales y cristianos, que no entramos en ello, sino por la mera comparación que se establece. A partir de este momento, queda claro que la frontera étnica que separa al religioso de sus feligreses se alza como una gigantesca barrera, imposible de traspasar. Mejor dicho, es infranqueable para el nativo; el fraile la puede cruzar siempre que lo cree oportuno, aunque el objeto del tránsito vendrá siempre definido por los intereses de la religión católica y sus apóstoles hispanos.

Tras esta desalmada introducción, el P. Azcárate ataca a hombres y mujeres filipinos por su indumentaria (v. 21-28); curiosamente, no escapan de sus dardos las féminas, a quienes la mayor parte de los religiosos suele situar en un nivel (de moralidad, inteligencia y laboriosidad) mucho más elevado que el presuntamente ocupado por los varones. La falsa o forzada religiosidad nativa vuelve a salir a colación en los versos 29 a 36, aunque lo que en realidad demuestran los argumentos presentados por el fraile es la incapacidad del clero regular para adoctrinar adecuadamente a los nativos. De todas formas, los riesgos que asumen los creyentes por su débil religiosidad son ciertamente importantes. Que coman carne los viernes y durante la cuaresma es un pecado que los párrocos pueden sospechar o realmente conocer, aunque quizás les sea difícil de

23. Así las califica el historiador catalán Josep M. Pradera en su magnífico libro Filipinas, la colonia más peculiar: la hacienda pública en la definición de la política colonial, 1762-1868. Madrid, 1999. 
recriminar si se les plantea el pretexto de la falta de pescado. Pero lo que la misma copla deja meridianamente claro es que, ante otras conductas reprobables o directamente pecaminosas (v. 33-36), el castigo físico, los tristemente famosos azotes con la vara de bejuco, están a la orden del día ${ }^{24}$.

Luego retornará a la moral de los filipinos, pero antes dedica el P. José un buen número de estrofas (v. 37 a 72) al ámbito doméstico en el que habita su rebaño. En primer lugar, al dominico parece molestarle especialmente el carácter liviano de sus viviendas, el estar construidas con maderas y cañas, algo propio de todo el archipiélago, así como el hecho de concentrarse la mayor parte de los enseres y de las actividades en un solo espacio compartido ${ }^{25}$. Ciertamente, la profusión de objetos y útiles diversos, de alimentos, de cruces y de estampas religiosas y el pobre y escueto ajuar presente en la inmensa mayoría de las viviendas nativas no tendría por qué dar origen a tanto desprecio. En no pocos pueblos españoles, que seguramente conoce el religioso, el panorama que ofrecen las viviendas a mediados del XVIII no debe de ser mucho más vistoso que el documentado en Paniqui; es más, tanto el tipo de materiales como la estructura de la casa filipina permiten sin duda una ventilación mucho más intensa que la que se puede lograr en una vivienda de piedra cerrada literalmente a cal y canto, a pesar del calor y de la humedad del clima filipino. Llama especialmente la atención ese rechazo a la profusión de cruces e imágenes de santos que, obviamente, el religioso interpreta como una muestra de fetichismo y no de fervor cristiano. De nuevo parece olvidarse nuestro protagonista de dónde surge todo aquello, de que es precisamente la muy fetichista parafernalia del culto católico el factor que no sólo permite sino que potencia tal orientación de la religiosidad popular. Por tanto, ni siquiera el hecho de compartir, al menos de modo formal, una misma religión ayuda a desmontar la frontera étnica; de hecho, las formas de poner en prácticas las creencias religiosas (las populares, de un lado, y las presuntamente ortodoxas u oficiales, de otro) ahondan el foso que separa a nativos y frailes. Y en seguida surge la frontera social: según el dominico, si el ajuar de una vivienda nativa es de mayor calidad, "si alguno tiene más", es porque lo ha obtenido en "mala feria" (v. 72), porque lo ha robado. Aquí una vez más vuelve a mostrarse el P. Azcárate muy poco respetuoso con la verdad pues, al margen de corruptelas (que "haberlas, haylas" en Filipinas, tanto en el mundo nativo como, y sobre todo, en el español), en Paniqui ha de

24. El castigo mediante azotes, casi siempre con vara de bejuco, fue muy común durante la mayor parte de la etapa española, siendo los perpetradores tanto los religiosos como los administradores civiles, pero también, y en ocasiones con mayor saña, las propias autoridades locales indígenas. En la inmensa mayoría de las ocasiones la pena se infligía completamente al margen de la legalidad.

25. Los religiosos regulares no dejaron nunca de condenar la "funesta" costumbre filipina de compartir hombres y mujeres las zonas de sueño y descanso de las viviendas, presunto origen de conductas terriblemente pecaminosas, agravadas por los lazos de parentesco. 
existir un estamento nativo privilegiado, una "principalía", alguno de cuyos miembros tiene que gozar de un nivel de vida más elevado que el propio del "común de los indios", y tal circunstancia no tiene por qué sustentarse necesariamente en el robo y la corrupción ${ }^{26}$.

Después de despacharse a gusto con sus moradas, retorna Fr. José a la moral y los valores del indio. Primero le toca el turno al tópico fatalismo del filipino, a su presunta insensibilidad ante las desgracias y la muerte. Lo curioso es que ahora esa "gran pachorra" (v. 75) se cataloga no solo como una especie de falta menor, sino decididamente como una "mala acción". El presunto fatalismo del indio nunca ha sido tal: se trata siempre de un mecanismo de adaptación (bastante extendido en todo tiempo y lugar) que protege a las personas ante situaciones que escapan a su control (la muerte, los tifones, las inundaciones, los terremotos, los incendios) y que les permite retomar un control relativo de la situación una vez superada o simplemente pasada la crisis. Luego nos ilustra el dominico sobre otra "debilidad" moral del indio: sobre el hecho de que es capaz de lamentarse públicamente de su falta de entendimiento (v. 83); es decir, que el filipino reconoce y presuntamente asume que su capacidad de raciocinio es limitada, en todo caso inferior a la del español y, por supuesto, a la del fraile que le tutela. Lo usual, asegura el P. Azcárate, es que las personas se mortifiquen por su falta de memoria, no por su escasa inteligencia: jamás había escuchado esa "cantinela". Y en tal confesión, afirma el fraile, "no hay misterio" (v. 87), es decir, resulta sencillamente cierta. Nuevamente el complejo de superioridad del dominico le vuelve a cegar. Cuando un filipino, o cualquier otro individuo, asume sus presuntas "limitaciones intelectuales" ante un interlocutor que posee un estatus social, económico, político y "étnico" objetivamente o presuntamente superior al suyo, lo único que hace es dar muestras de sagacidad y pragmatismo o, si se prefiere, de cierto carácter acomodaticio. El nativo filipino tiene que aceptar su papel subordinado para poder salir adelante $y$, para lograrlo, no existe recurso mejor que mostrarse ante sus presuntos superiores como éstos piensan que debe hacerlo: siempre sumiso y conocedor de sus profundas limitaciones. Otra cosa es que, por detrás y en las sombras (y en ocasiones incluso de frente y a las claras), determinados miembros de las

26. Sobre la corrupción de la administración en Filipinas (con anotaciones también sobre la actitud de los frailes), véase el completo y detallado estudio de Xavier Huetz de Lemps: L'Archipel des Épices. La corruption de l'administration espagnole aux Philippines (fin XVIII - fin XIXe siècle). Madrid, 2006. Aunque centrado en el periodo que abarca desde finales del siglo XVIII a finales del XIX, ofrece muy interesantes análisis útiles también para momentos anteriores. Un ejemplo de las complejas relaciones que se documentan (entre frailes, élites nativas y alcaldes mayores) en no pocas provincias de Filipinas en la segunda mitad del siglo XVIII, puede verse en L. A. Sánchez Gómez: "Sobre jueces, gobernadores, gobernadorcillos y frailes (Filipinas, 1769-1771)". Revista Española del Pacífico 11 (2000), pp. 99-127. 
principalías sean capaces de enfrentarse a frailes y administradores españoles, gestionando adecuadamente apoyos y alianzas de muy variada índole ${ }^{27}$.

Una vez fiscalizadas las acciones y los sentimientos del nativo, Fr. José Azcárate dedica casi medio centenar de versos a describir la diversidad del suelo filipino (v. 89-136). Con el transcurso del tiempo, la imagen que los españoles han construido sobre la geografía, la fauna, la flora y el clima filipinos se ha ido modificando, aunque nunca se ha perfilado una estampa única, pues cada gremio socio-profesional ha interpretado el sentido de tan exótico espacio de modo diferenciado. En 1760, cuando se redactan las coplas, España no ha desarrollado aún estudios científicos sistematizados sobre la "geografía botánica" (que siempre interesa mucho más que la fauna) de Filipinas. Es un cuarto de siglo después, a partir de finales de la década de 1780, cuando los estudios realizados por Juan de Cuéllar dan inicio una rica tradición que continúa, con altibajos, durante casi todo el siglo XIX, unas veces de la mano de religiosos y otras a través de iniciativas y proyectos oficiales ${ }^{28}$. En la época que nos ocupa, aún no se ha perfilado claramente el verdadero valor y las limitaciones del clima y del medio filipinos en relación con la producción de recursos vegetales. Entonces (pero también en épocas posteriores) la visión del territorio filipino oscila entre su consideración como auténtico edén tropical, dada la exhuberancia de sus selvas y la riqueza de la producción agraria de determinadas zonas, o como verdadero infierno, como la materialización opresiva, asfixiante y patogénica de unas tierras salvajes, casi vírgenes, en las que solo pueden habitar unas gentes igualmente salvajes, no el hombre blanco, europeo y civilizado ${ }^{29}$. El P. Azcárate opta claramente

27. Sobre la situación de las principalías nativas (y sus relaciones con los frailes y la administración civil española) durante los siglos XVII y XVIII, véase L. A. Sánchez Gómez: "Las élites nativas y la construcción colonial de Filipinas (1565-1789)", L. Cabrero (ed.). España y el Pacífico. Legazpi. Madrid, 2004, vol. II, pp. 37-70.

28. Además de los trabajos de Cuéllar (desarrollados entre 1786 y 1796) y de los derivados de la expedición Malaspina (1792), destaca especialmente la obra de Fr. Manuel Blanco (17781845), autor de la famosísima Flora de Filipinas, que tiene una primera edición en 1837 y que es continuada posteriormente por otros miembros de la orden agustiniana, apareciendo la tercera edición -en cuatro volúmenes de texto y dos de láminas- entre 1877 y 1883 , con nuevos textos redactados por los PP. Ignacio Mercado, Antonio Llanos, Andrés Naves y Celestino Fernández Villar. Desde la administración, apenas se hace nada hasta bien avanzado el siglo XIX. Es en 1863 cuando se organiza una Inspección General de Montes y comienzan los trabajos metódicos. Más tarde, por real decreto de 21 de julio de 1876, puesto en práctica en marzo de 1878, se crea una "Comisión de la flora y estadística forestal de Filipinas", de la que es presidente, en su sección botánica, Sebastián Vidal y Soler, que logra importantes resultados tanto en los estudios botánicos como en los zoológicos. Desgraciadamente, y de ello se lamentan todos los contemporáneos que escriben sobre el tema, la comisión se suprime, igual que otra creada de carácter geográfico-geológico, por real decreto de 26 de febrero de 1886, pasando a desarrollar esa labor la Inspección General de Montes.

29. La tercera imagen es la que articulan los botánicos e ingenieros de montes (éstos ya en el siglo XIX), que valoran en su justo términos las ventajas y los inconvenientes de los suelos y el clima filipinos. 
por la visión paradisíaca del paisaje filipino, y lo hace para reforzar aún más la negativa imagen que nos ofrece de sus habitantes, quienes, pese a vivir en un presunto paraíso, son incapaces de rentabilizar los recursos que la naturaleza de manera tan generosa les ofrece. Cita, eso sí, los peligros de su fauna (cocodrilos y serpientes) y, por otra parte, aunque ensalza la riqueza de sus aguas, luego resulta que la "enfermedad cagalera" (v. 130) es responsable de la muerte de incontables filipinos. Tampoco se olvida de terremotos y baguios (tifones), aunque sólo los menciona como sardónica justificación (recreando así la imagen harto inestable de una persona alcoholizada) de las presuntas borracheras de las que serían víctimas los nativos. Finalmente, a pesar de calificar de "vergel" a sus montes, su escaso aprecio por aquellas islas y sus habitantes le obliga a concluir que las Filipinas son "una oración imperfecta" (v. 136).

En los versos 137 a 148 hace el P. José un muy escueto y parcial balance de la situación socioeconómica del archipiélago, aunque su referente es casi en exclusiva la capital del archipiélago. Atravesamos así una nueva frontera: la que separa al mundo urbano, español y oficial por excelencia del resto del archipiélago, un mundo rural, nativo y esencialmente popular. La ciudad de Manila se nos muestra como una especie de foco de atracción que embelesa a los incautos con sombras de pompa y riqueza. Allí, lo que en realidad gobierna es el orgullo pecaminoso y el alejamiento del hombre respecto de su Dios (dorsa habentes contra templum [Domini], es decir, las gentes viven "de espaldas al templo del Señor") (v. 141). Luego, la siguiente referencia a cenizas ("favilas") y pavesas quizás deba interpretarse como que, en definitiva, y a pesar de las vanas ilusiones y de los aires de grandeza, todos somos mortales ("polvo al polvo y cenizas a las cenizas"). Tan oscuros nubarrones los ennegrece por completo una actividad comercial depauperada y unos arbitrios que nada resuelven, salvo quizás algunas economías particulares.

Hemos hecho mención a un horizonte filipino ennegrecido, pero el P. Azcárate aún tiene muchas desgracias de las que informar: el panorama se vuelve, así, sencillamente catastrófico ${ }^{30}$. El religioso dedica más de medio centenar de versos (149-204) a describir de forma bastante pormenorizada los terribles sufrimientos que padecen los cristianos filipinos por las incursiones y asaltos de "moros" (de Mindanao y Joló) e infieles (de las montañas de Luzón); ambos contextos configuran sedas fronteras interiores que nunca serían atravesadas de forma decidida e inapelable por los españoles. Las razzias moras no afectan en realidad a la provincia de Pangasinán, pues ésta se sitúa en la zona central de Luzón, alejada de

30. Si el religioso hubiera demorado un par de años la redacción de sus coplas, su descripción de Filipinas habría sido, ahora sí, verdaderamente horrenda, tanto para él (que la conoce y la sufre) como para los intereses españoles en el archipiélago. En efecto, en 1762 los ingleses ocupan Manila y al año siguiente, en un contexto de gran inestabilidad política y social, se producen graves levantamientos nativos en varias provincias, y muy especialmente en Pangasinán, que son reprimidos a sangre y fuego por los españoles. 
los territorios de dominio musulmán y de las costas que éstos acechan ${ }^{31}$. Sin embargo, las islas Visayas y las provincias más meridionales de la propia isla de Luzón sí padecen esos asaltos de la "moruna fiereza" (recurrentes durante casi toda la etapa española), con su consiguiente saldo de destrucción, raptos y muerte. El segundo foco de tensión e inseguridad para los cristianos es el que tiene su origen en los infieles de las montañas, a los que los españoles suelen denominar de forma genérica "igorrotes" ${ }^{\prime 2}$. Son éstos quienes hacen uso de "flechas envenenadas", quienes practican efectivamente (al menos algunos grupos) el corte ritual de cabezas y a quienes se acusa de desarrollar prácticas antropófagas. No obstante, la canibalesca y vampiresca imagen que nos pinta el religioso está muy alejada de la realidad. Pocos más datos ofrece el dominico de estos infieles: se refiere únicamente a su indumentaria (el famoso taparrabos) y deja caer la típica y tópica denuncia de sodomía (v. 201-204), muy común en textos racistas sobre pueblos "salvajes" escritos casi en cualquier tiempo y lugar.

La penúltima sección de las coplas (v. 205-248) la reserva su autor para ofrecer alguna información sobre sus hermanos de orden misioneros en Extremo Oriente $y$, en definitiva, sobre su propia persona, aunque sobre ésta prácticamente no dice nada. En realidad, el objetivo último (y primero) de estos versos es resaltar la figura del misionero, de un misionero que es enviado al otro lado del mundo, a unas tierras a las que se refiere como "palestra" y cuyo significado debemos interpretar de modo literal: "lugar donde antiguamente se lidiaba

31. El término moro lo aplican los españoles a los pueblos malayos de religión musulmana con los que, literalmente, se topan en Filipinas nada más echar pie a tierra en las islas. Aunque en un principio tiene, indudablemente, un carácter peyorativo, semejante al que de hecho ofrece en la Península, con el paso del tiempo se convierte en la denominación utilizada de forma genérica para nombrar a los filipinos miembros del islam. Incluso los propios musulmanes lo hacen suyo, a modo de rasgo de identidad. Véase en este sentido la proliferación del término "moro" en organizaciones de todo tipo, incluidas las políticas de carácter independentista, como pueden ser el Moro National Liberation Front o el Moro Islamic Liberation Front, que pretenden la independencia de la comunidad Bangsa Moro -literalmente, "nación o pueblo moro"-, esto es, de la población mora y de los territorios de Sulú (archipiélago de Joló), Mindanao, Basilan y Palawan (la antigua Paragua). El primero, no obstante, firmó en 1996 un acuerdo con el gobierno filipino por el que se concedía cierta autonomía a la "Región Autónoma Musulmana de Mindanao", integrándose en la vida política. El segundo lo rechazó, continuando con la lucha armada de carácter terrorista.

32. Aunque el P. Azcárate no lo emplea, el término igorrote es utilizado por los españoles para nombrar a un buen número de pueblos primitivos de las montañas de Luzón, ya que, al parecer, las gentes de las tierras bajas vecinas denominaban a aquéllos igolot, esto es, gente de la montaña, dado que golot es un término del tagalo antiguo que significa sierra o cordillera. Si bien todavía puede encontrarse en alguna obra etnográfica contemporánea, lo cierto es que la denominación genérica de igorrotes fue desterrada desde hace algunas décadas de la bibliografía antropológica. Los pueblos infieles a los que se refiere el P. Azcárte serían, entre otros, apayaos, bontocs, ifugaos, kalingas, ilongotes y gaddangs. Además de estas etnias, el dominico quizás también puede tener en mente, al referirse a comunidades infieles, a pueblos negritos, cazadores-colectores de piel oscura y baja estatura, cuyas denominaciones nativas varían (itas, agtas, aetas, etc.). 
o luchaba" (según el DRAE). Esto es, la tremebunda imagen que el dominico nos ha ofrecido de Filipinas y de los filipinos a lo largo de sus pésimas coplas sirve en realidad para elevar directamente a las alturas a quien es capaz de sobrevivir en semejante infierno y de hacerlo, además, honrando presuntamente a Dios con su labor misional y pastoral. De este modo, cualquier misionero se convierte automáticamente en mártir o, al menos, así debería de ser considerado. Anota el P. Azcárate que, después de tres o cuatro meses de haber llegado a Manila, el provincial de la orden reparte las "boletas" o cédulas de viaje y, con ellas, el respectivo destino que a cada fraile le corresponde. Los más capacitados y devotos son enviados a Tonkín (Vietnam) y China, territorios de antigua expansión misional dominicana. Otros, quizás los más jóvenes pero con afán de superación, pasan un tiempo en el Parián de Manila, un arrabal de la capital filipina (con importante mercado) habitado mayoritariamente por chinos (también Ilamados sangleyes), cuya parroquia estuvo a cargo de los dominicos desde los inicios de su presencia en el archipiélago. La población china conversa del antiguo Parián fue trasladada en los últimos años del siglo XVI al barrio manilense de Binondo, convirtiéndose éste en el núcleo de la evangelización de la población china en la capital del archipiélago hasta la actualidad. No obstante, en 1617 los dominicos vuelven a hacerse cargo de la parroquia del antiguo Parián, cometido que pierden en 1768 a favor del clero secular ${ }^{33}$. Como anota González Pola, la tarea misional desarrollada por los dominicos con los chinos de Manila les ha resultado siempre (y les sigue resultando) enormemente rentable, ya que ha facilitado el aprendizaje del chino (del mandarín y quizás de algún otro dialecto) y el acercamiento a los rudimentos de la cultura china, conocimientos preciosos para la formación de aquellos misioneros que posteriormente serían enviados a evangelizar en China.

Los otros dos destinos citados, las provincias de Cagayán y Pangasinán (ambas, en el siglo XVIII, de extensión bastante mayor a la actual), son las dos grandes áreas de actividad misional dominicana en Filipinas (además de la mucho más reducida provincia de Bataán, las islas Batanes -desde 1783-y las Babuyanes y diversas poblaciones en otras provincias), ocupando ambas buena parte de la mitad norte de Luzón. Aunque durante los siglos XVIII y XIX los dominicos abren nuevos centros de evangelización en todas esas áreas, se puede afirmar que en 1760 la inmensa mayoría de la población que habita las zonas Ilanas ha sido ya cristianizada. Es cierto que aún continúa desarrollándose una cierta actividad apostólica entre las comunidades infieles de las montañas y valles de Cagayán, pero tanto su intensidad como su éxito habrán de ser siempre, hasta el final de la presencia española en el archipiélago, muy escasos. Por tanto, la mayoría de los misioneros destinados a las provincias de Cagayán y Pangasinán (como el P. Azcárate) pasa a hacerse cargo de parroquias ya establecidas, que se

33. M. González Pola, "Evangelización... (siglo XVII)”, p. 479. 
localizan en poblaciones evangelizadas desde hace al menos un siglo. El modelo de relaciones sociales, políticas y económicas establecido entre los nativos, sus élites locales, los frailes, la lejana administración civil provincial (española) y los muy escasos ciudadanos españoles o extranjeros que por allí pueden pulular está ya bastante bien estructurado en aquellas fechas. Y, aunque siempre existen tensiones y desequilibrios, los párrocos que administran esas parroquias desarrollan una labor que se encuentra mucho más cercana a la tarea pastoral cotidiana propia de un sacerdote secular que a la empresa evangelizadora de un misionero. Por supuesto, esta afirmación no puede dejar de tomarse con cierta prevención, ya que las condiciones de vida y de sociabilidad de estos religiosos son muy diferentes a las de la inmensa mayoría de los párrocos de la España peninsular de entonces. Pero son precisamente el aislamiento y la omnipresencia de los frailes en los pueblos filipinos dos de los factores que más singularizan su actividad, aunque sin duda el factor determinante es la extensión y profundidad de los ámbitos sociales, políticos y económicos que controlan, o sobre los que ejercen una decisiva influencia, circunstancia en buena medida derivada de una especie de delegación (entre oficial y oficiosa) hecha a los religiosos por la administración española. En resumen, el P. Azcárate es destinado a Paniqui y allí administra su parroquia y sus feligreses de un modo que debe de resultar, si interpretamos adecuadamente sus coplas, cuanto menos marcadamente autoritario.

Menciona nuestro fraile la circunstancia de que en tres meses los misioneros son capaces de hablar correctamente la lengua de la comunidad misionada (v. 225-229). Quizás sea un margen de tiempo excesivamente corto, pero lo cierto es que los frailes españoles logran un éxito más que notable en el conocimiento de las lenguas nativas, y esto es algo que casi todos tienen que alcanzar estando ya en el lugar de destino, dado que la enseñanza previa de la inmensa mayoría de las lenguas y dialectos existentes en el archipiélago resulta sencillamente imposible. Por supuesto, los frailes no se limitan a aprender el idioma nativo: muchos de ellos traducen textos sagrados y editan una ingente cantidad de novenas y obras litúrgicas, pero también publican interesantes y muy útiles gramáticas y diccionarios de las principales lenguas. En realidad, esas excelentes dotes de aprendizaje de los misioneros han estado históricamente asociadas a su incapacidad o, mejor dicho, a su rechazo a generalizar el conocimiento del español entre los nativos, a pesar de ser los responsables casi exclusivos de todos los ámbitos educativos en el archipiélago. Precisamente esta circunstancia hace que muchos políticos y personajes españoles (y filipinos) de orientación liberal acusen a los frailes de ser antiespañoles, aunque esto se documenta especialmente en el siglo XIX, en su segunda mitad, no tanto en épocas anteriores ${ }^{34}$. La acusación, o la crítica, la ha hecho suya parte de la his-

34. Pero, curiosamente, también en este asunto se ve implicado nuestro protagonista. Según anota en su breve reseña biográfica el P. Neira (Misioneros, vol. I, p. 347-348), el P. Azcárate 
toriografía moderna sobre la presencia española en Filipinas y, pese a todo lo que se pueda argumentar en su contra, es indudable que los frailes optan desde un primer momento por limitar la enseñanza del español casi únicamente a los nativos (y también a los mestizos de chino y de español) que pueden tener más directamente bajo su tutela y control. De este modo, el fraile puede adentrarse en los entresijos de las culturas nativas, mientras que la inmensa mayoría de los filipinos queda incapacitada para conocer, interpretar y rentabilizar el código lingüístico español; queda desposeída, en definitiva, del poder que otorga el conocimiento de la lengua del imperio. Los pocos que pueden escapar a esta verdadera "castración cultural" son aquellos escasos filipinos que, sobre todo desde el siglo XVIII pero con mucha más fuerza en el XIX, se encuentran filogénica y culturalmente a caballo de dos mundos: el nativo y el españo ${ }^{35}$. Nos referimos al mestizo de español, que precisamente ha sido la categoría de ciudadano (o de súbdito) filipino más denostada por los frailes por esa privilegiada situación suya, que le permite conocer y acceder tanto a las claves lingüísticas y culturales del mundo nativo como del españo ${ }^{36}$.

En los versos que siguen, Fr. José Azcárate se muestra muy agradecido a los prelados, parece excesivamente condescendiente, como si temiera, o quizás

escribe una "Respuesta al siniestro Informe del Cabildo a S.M. culpando a los religiosos de que, por su culpa, los naturales de Filipinas no aprenden el castellano". Aunque la cita de otra forma, el P. Neira toma el dato de una obra redactada en 1960 por Fr. Mariano Velasco, titulada Ensayo de bibliografía de la Provincia del Santísimo Rosario de Filipinas (Manila, seis volúmenes mecanografiados), de la que se conserva copia en el Archivo de la Provincia Dominicana de Nuestra Señora del Rosario, sito en el Convento de Santo Tomás, en Ávila. Sobre este archivo (y otros fondos documentales filipinistas), puede consultarse el libro de Patricio Hidalgo Nuchera: Guía de fuentes manuscritas para la historia de Filipinas conservadas en España. Madrid, 1998. Desconocemos si éste u otro centro guarda copia del escrito del P. Azcárate.

35. Los mestizos de chino no fueron considerados por los frailes de forma tan negativa como los de español.

36. Precisamente una de las más tremebundas imágenes que del mestizo español nos ofrece un fraile sale de la pluma de un dominico, aunque la redacta ya en la década de 1880. Nos referimos a una interesantísima obra de título harto protocolario (Exposición general de las Islas Filipinas en Madrid 1887. Comisión Central de Manila. Memoria complementaria de la sección $2^{a}$ del programa. Pobladores aborígenes, razas existentes y sus variedades. Religión, usos y costumbres de los habitantes de Filipinas. Edición oficial. Manila, 1887) redactada por el dominico Fr. José María Ruiz y el jesuita P. Francisco Sánchez, siendo la parte que nos interesa (que también es la más extensa y atractiva de la obra) la escrita por el dominico. La franqueza y rotundidad con la que se expresan los frailes, sobre todo el P. Ruiz, hace que el arzobispo de Manila Fr. Pedro Payo, también dominico, prohíba la obra; los motivos: el contexto político que se vive tanto en la Península como en Filipinas en esos momentos no es ya el que conociera el P. Azcárate. Incluso en las islas, el objetivo -teórico y oficial, eso sí- de la administración civil es circunscribir la labor y la influencia de los religiosos al plano espiritual y a muy determinados ámbitos de actuación, salvo que interese circunstancialmente otra cosa. En este contexto, los religiosos tienen que medir mucho más sus palabras que en épocas anteriores. Sobre los contenidos de la memoria citada, véase L. A. Sánchez Gómez: Un imperio en la vitrina. El colonialismo español en el Pacífico y la Exposición de Filipinas de 1887. Madrid, 2003, pp. 273-296. 
deseara, que sus coplas Ilegasen a conocimiento de sus superiores. El ambiente que nos describe es sencillamente celestial: Dios y los prelados protegen a los misioneros, éstos se afanan "para cumplir cuanto ordenan" (v. 232) y todos, en definitiva, trabajan con todas sus fuerzas. El misionero siempre obedece y acude allí donde le ordenan para atender a "sus ovejas". Por supuesto, no le faltan "pesadumbres, mortificación ni penas" (v. 241-242), pero tales sacrificios hacen más excelsa su labor. No aparece atisbo alguno de autocrítica, ni una palabra se destina a reconocer unos errores o debilidades que, sin embargo, presenta como inherentes al indio filipino. Pero hemos de aceptar que el dominico no es tan inocente (con respecto a su propio entorno) como aparenta, pues antes de concluir nos insinúa algo que finalmente se guarda para sí. Afirma que lo recogido en sus coplas es "Io que es para todos / y lo que hay puertas afuera" (v. 245-246), pero anota que hay otras seguidillas, otras coplas, relativas a lo de "acá dentro de las puertas" (v. 248). En resumen: nos dice que ha contado lo que puede contar; ha hablado de Filipinas y de los filipinos, los ha denostado y hasta insultado, pero eso no es algo que pueda alterar su vida cotidiana o su condición de misionero y párroco. También se ha referido a su comunidad, pero lo ha hecho de modo extremadamente formal, casi como si de una declaración oficial se tratara. Sin embargo, asume que hay cuestiones internas que podrían interesar mucho de puertas afuera, y que suponemos se refieren al ámbito interno de la orden, a las relaciones existentes entre los misioneros, entre éstos y sus prelados, y quizás también al día a día de la vida de los párrocos en las poblaciones que administran. Lástima que al final nuestro dominico no se decida a trasladarnos en coplas, por muy malas que fueren, tan sugerentes temas; al menos, no tenemos noticia de que lo hiciera. Ahora somos nosotros quienes nos vemos obligados a detenernos ante esa nueva frontera, una frontera interna y absolutamente infranqueable.

El remate del manuscrito lo pone la despedida (v. 249-260). Lo de que es mejor terminar para no "chisquear" (o chiscar, esto es, hacer sacar chispas) a la musa parece que llega demasiado tarde o, mejor, que ni siquiera habría sido necesario mencionarlo: lo más probable es que la musa no supiera nunca de las pretensiones versificadoras del dominico. Luego, tras desear un feliz porvenir a su interlocutor y amigo (ese tal Fr. Julián Díaz ${ }^{37}$ ), nos informa del lugar (Paniqui) y del año (1760) en el que ha puesto fin a su engendro poético y se dedica a sí mismo unos cuantos apelativos, algo sardónicos y hasta condescendientemente insultantes. No me refiero, ¡Dios me libre!, a lo de vízcaíno, sino a lo de "medio burro". Y, en cuanto a lo de calificarse de "cierto quidán", el asunto es algo más singular y, si hemos acertado con la interpretación, un tanto sofisticado.

37. Fue también dominico. Nació en Toledo en 1716, murió en Puerto Real (Cádiz) en 1793. Estuvo en México entre 1737 y 1769 (Neira, Misioneros, vol. I, p. 329). 
El término "quidán", o "quidan", podría corresponderse con la voz kidang, de origen austronesio ${ }^{38}$, que identifica a alguna de las diversas especies de mouse deer (ciervo ratón o ciervo enano) originarias del sur y del sureste de Asia. En Filipinas se conocen varias especies de estos cérvidos, alguna de ellas endémica del archipiélago, aunque parece que allí no es de uso frecuente la voz kidang, que sí es común en Indonesia. En todo caso, si el P. Azcárate se identifica con un animal de esas características (ágil y, más que pequeño, algo "ratonil"), puede que nos esté indicando algo sobre su apariencia física y, quizás de manera más precisa, sobre su personalidad, una personalidad inquieta y puede que incluso algo marrullera. Lo de "medio burro" puede ser tanto una muestra de falsa modestia como, y con mayor probabilidad, el reconocimiento hiperbólico de unos orígenes plebeyos y/o de una formación no demasiado elevada ${ }^{39}$. Por último, su identificación con un "alma en pena" no es sino una muestra más, y en este caso definitiva, de que si el dominico no se presenta directamente como un mártir por Cristo, está a un paso de hacerlo. Bien, puede que exageremos: un alma en pena tiene poco que ver, por mucho que padezca en soledad, con un mártir cristiano. Quizás el asunto es mucho más simple, quizás Fr. José se siente realmente así: solo, anímicamente desvalido, como alma en pena. De todos modos, aunque ese estado de ánimo suyo fuera real en 1760, aunque su quehacer como párroco rural pudiera resultarle algo tedioso, sabemos que en 1765 es trasladado a Manila, lo que sin duda debe de suponer un cambio profundo en todos los ámbitos de su vida personal y social. ¿Se modifica entonces su visión del nativo filipino? No lo sabemos, pero muy probablemente no.

Vayamos ya a las conclusiones. Quizás, sólo quizás, fuera injusto que asumiéramos el tono marcadamente insultante, y hasta decididamente racista, de estas coplas como rasgo definidor del modelo de relaciones articulado por los dominicos (por los frailes, en general) en su día a día con los nativos. Por supuesto, tampoco sería aceptable optar por una visión hagiográfica y complaciente, como ha sido norma en la historiografía religiosa y en buena parte del escuálido filipinismo español (presuntamente laico) hasta comienzos de la década de 1980. En principio, el escrito en cuestión debe entenderse como lo que es o, mejor, como lo que parece ser: las reflexiones de un misionero más o menos fervoroso encargado de la cura de almas en unas tierras tan lejanas que poco les falta para ser consideradas el fin del mundo; que tiene bajo su "tutela" espiritual a cientos, tal vez a miles, de campesinos pobres cuya forma de vida es extremadamente sencilla, muy rudimentaria, que han aceptado la presencia de los frailes y de la religión católica como una especie de mal menor, pero también (y al

38. Debo esta identificación al historiador filipino John D. Blanco (de la Universidad de California en San Diego), a quien recurrí expresamente solicitando ayuda.

39. Circunstancia que, como hemos visto, no le impide ocupar cargos de cierta relevancia en Manila. 
igual que cualquier campesino español contemporáneo) como un recurso sobrenatural al que acudir ante situaciones de crisis irresolubles por otros cauces. Inmerso en ese entorno, el P. Azcárate mira a sus feligreses como seres inferiores, incapaces de acariciar siquiera el nivel de desarrollo intelectual, moral y material presuntamente alcanzado por un español. Pueden ser hijos de Dios, pero son unos hijos anclados de por vida en la etapa infantil, caprichosos, vagos y desagradecidos, incluso en ocasiones decididamente "salvajes". El desprecio que manifiesta ante los nativos no es ciertamente muy cristiano, pero sí muy común entre quien se sabe y se siente superior; superior por el poder que le confieren sus conocimientos técnicos, su posición social, su capacidad para controlar todos o casi todos los resortes de la vida de aquellos a quienes "tutela". Pese a todo, hemos de reconocer que no sabemos si sus versos son un reflejo ajustado de su modo de relacionarse con los parroquianos o si se redactan simplemente para abrir una de vía de escape a las tensiones cotidianas; es decir, si recogen realmente su forma de pensar y actuar o si son el mero receptáculo de sus frustraciones. Aunque la comparación pueda parece algo disparatada, quizás las coplas cumplen un cometido similar al famoso diario del antropólogo Bronislaw Malinowski, cuyos contenidos tanta polémica suscitaron tras su publicación debido (entre otras cuestiones) al marcado carácter racista e insultante de no pocas de las anotaciones que el autor hace sobre "sus" nativos trobriandeses.

El modelo de interpretación de la sociedad nativa que nos presenta nuestro protagonista no es en modo alguno excepcional, aunque quizás en este caso se muestra algo, sólo un poco, más racialmente exacerbado. Es relativamente frecuente encontrar testimonios de reflexiones y conductas racistas entre miembros del clero regular asentado en Filipinas, y esto es algo que tratan de rentabilizar los ilustrados en su lucha política, durante la segunda mitad del siglo XIX, en favor de la reducción de la influencia del clero, de la introducción de reformas no sólo administrativas sino políticas y, en definitiva, en pro del reconocimiento de la "mayoría de edad" de al menos una parte relevante de la sociedad filipina ${ }^{40}$. De todas formas, podría objetarse que, si fuere cierta la indicación que acabamos de hacer sobre el despotismo de los frailes, las relaciones mantenidas históricamente entre los pastores católicos y su rebaño filipino no podrían haber llegado hasta donde lo han hecho; pero la cuestión no es tan sencilla. La expansión del cristianismo, y de forma aún más intensa la del catolicismo, ha sido por lo general muy exitosa. Filipinas es el ejemplo más destacado, en todo tiempo y lugar, del triunfo de la empresa evangelizadora católica. Visto con cierta perspectiva, resulta casi inexplicable (ciertamente "milagroso") asumir que unos pocos cientos de religiosos (la mayoría con muy escasa for-

40. Opiniones similares a las del P. Azcárate son las que manifiestan, al socaire de la organización de la Exposición de Filipinas de 1887, diversos frailes residentes en Filipinas. Véase L. A. Sánchez Gómez, Un imperio, pp. 264-272. 
mación) fueran capaces de atraer y en buen medida de subyugar a cientos de miles de nativos sobre quienes desconocían prácticamente todo; $y$ hace tiempo que esos cientos de miles se han convertido en varias decenas de millones de personas. Con el paso del tiempo, el férreo control de cuerpos y voluntades tiene que haber desempeñado un papel relevante en la consolidación del sistema. Sin embargo, ya hemos adelantado que el repertorio de recursos propiciatorios, relativamente asequibles, que ofrece la religión católica tiene que haber contribuido a su éxito desde los momentos iniciales de la obra evangelizadora. Tampoco habría que infravalorar el impacto causado por la propia imagen personal de los misioneros, las ventajas que podía ofrecer a los filipinos "del común" la ruptura del modelo de jerarquización estamental tradicional y la introducción de nuevos mecanismos de movilidad social ${ }^{41}$ y, por supuesto, en modo alguno hemos de olvidarnos de la presión ejercida por el poder civil y militar colonial.

Volviendo al documento, hemos de concluir que la acusación que hace el P. Azcárate contra sus feligreses de estar dorsa habentes contra templum [Domini] puede ser cierta desde una perspectiva dogmática o doctrinal, pero es claramente injusta si con ello pretende denunciar una presunta "falsa religiosidad" del pueblo ${ }^{42}$; además, dicha falta sería achacable en todo caso a los misioneros. Quien realmente parece estar de espaldas contra algo o contra alguien es el propio dominico, de quien se podría decir que se muestra dorsa habentes contra populum, contra el pueblo de Filipinas, contra sus propios feligreses.

\section{“Descripción en Copla de las Yslas Filipinas y de sus Naturales, por el P. Fr. José Azcárate, del orden de Predicadores, a su amigo Fr. Julián Díaz"43}

1 Ya que, amigo Fr. Julián, del fin del Mundo deseas saber escritas por mí las novedades más ciertas,

5 no me escuso a daros gusto, que tal vez si te recrean les darás algún asenso,

41. Desde muy pronto, las alteraciones producidas en la estructura social tratan de ser reequilibradas por las élites nativas, por los miembros de las "principalías", que se ven forzados a articular un complejo sistema de relaciones con los frailes, sistema en el que la negociación de lealtades y enfrentamientos se desarrolla en un contexto de tenso e inestable equilibrio. De todas formas, en muchas ocasiones los indios "del común" obtienen el apoyo del clero regular frente a los abusos de sus propias autoridades nativas.

42. Aunque la indicación se hace al comentar el carácter de la población de Manila, es obvio que el dominico la proyecta sobre el conjunto de la población nativa filipina, por muchas imágenes de santos y por muchos crucifijos que cuelguen de las paredes de sus viviendas.

43. Hemos trascrito el texto modificando únicamente la puntuación y la acentuación. Se mantiene la ortografía original y se respeta la aleatoria utilización de las mayúsculas. 
aunque son de longas tierras.

Déjame que me santigüe,

10 que esta diligencia es buena

para salir con acierto

de tan difícil materia.

Ya sabes que Filipinas

se difine aquesta tierra,

15 pero es mejor la llames

segunda Sierra Morena,

cuyos naturales son

más blancos que mi correa, como Madrid olorosos,

20 Santos como Ana Bolena.

Todo varón rico y pobre, de pueblo y de sementera ${ }^{44}$, le verás de punta en blanco armado con su rodela.

25 Ellas no son de pintar, pues son como la veleta que con el viento que corre mudan figura y librea.

Arroz y pescado comen,

30 mas los viernes y cuaresma, dicen que por no haver más, carne cenan y meriendan.

Oyen Misa por temor, ayunan tal vez por fuerza

35 y por no llevar azotes en Cuaresma se confiesan.

Duermen sobre un mal petate sobre cañas y maderas, en un aposento todos,

$40 \quad$ los de adentro y los de afuera.

Sus casas son cuatro palos, el tejado solo yerba, el piso cañas partidas como también la escalera.

44. El indio "de pueblo" es el que habita en los núcleos rurales propiamente dichos, originales o creados mediante el sistema de "reducción a poblado". El nativo "de sementera" es aquel que vive aislado en el monte, cultivando las tierras fuera de la supervisión directa del párroco y de las autoridades locales nativas. 
45 Las cañas entretejidas es pared de la vivienda. Cuarto, salas y cocina entra todo en una pieza. Perro, Gallo y Cochinillo,

50 arroz, pescado y las flechas, candil, cántaros y frenos también en la sala cuelgan. Cuatrocientos San Vicentes por los rincones los cuelgan,

55 pellejos de baca y cuernos y un crucifijo sin piernas. Una procesión de cruces y unas cuantas ratoneras al lado de un San Macario

60 los clavan junto a la puerta. Una mesa todo mugre tienen también por grandeza y no necesitan sillas, por razón de ser pigmea ${ }^{45}$.

65 Un cañuto con aceite tienen que la casa apesta ${ }^{46}$, vinagre, sal y pellejos y una guitarrilla vieja. A esto pues se reduce

70 todo su ajuar y maleta, y si alguno tiene más, es havido en mala feria.

$\mathrm{Ni}$ en la vida ni en la muerte se les ve una acción buena,

75 siendo de tan gran pachorra que ni en la muerte se alteran. Contra todas las Naciones es lo que en ellos se observa, pues confiesan que no tienen

80 entendimiento ni testa. Por lo regular el hombre

45. Se refiere a la mesa, que tiene muy escasa altura.

46. Debe de tratarse de un recipiente de caña, con aceite, empleado para el alumbrado del hogar. 
de la memoria se queja, pero del entendimiento jamás oí tal cantinela.

85 Solo el Yndio en Filipinas nos vende aquesta fineza, temo no aya aquí misterio para más confusión nuestra. Dioles Dios, por su Piedad,

90 para habitación la tierra de amenidad y delicias que no cave más perfecta. Es un ameno Vergel, todo Monte, todo Selva.

95 Abastecido de frutos, de animales y riquezas. Jamás se agotan los Montes, siempre en su verdor campean. Sus Ilanuras son boticas

100 de Medicinales yerbas. Caudalosísimos ríos de potables aguas riegan las Provincias y los Pueblos, Montes y las Sementeras.

105 En ellos hay un gran peligro de caimanes ${ }^{47}$, que son fieras que un Caballo, Baca u Hombre de un bocado se lo llevan. El que navega en Chalupa

110 y aun el que al río se acerca ambos peligran, porque con astucia los espera. Mataron uno en mi pueblo $y$ tres hombres muertos eran

115 los que tenía en el vientre y en un envoltorio de yerbas. En el agua es donde habitan por lo común, pero a tierra sale de noche a cazar

47. Se trata del relativamente común Crocodylus porosus, que habita en zonas del sur y del sureste de Asia y del norte de Australia. Es el mayor reptil que existe, pudiendo alcanzar los seis metros de longitud. Su fiereza y peligrosidad son bien conocidas. 
120 la Caimana, por ligera.

En la tierra los peligros

a cada paso se encuentran,

y son mortales aquí

mordeduras de culebras.

125 Pues de rayos y temblores

es columpio y es tormenta,

y así hay muchos con baibenes

y achispados cuantos quieras.

No te espreso los que han muerto

130 de enfermedad cagalera, porque sería imposible reducírtelos a cuenta.

Aquí no hay más novedad sino el ser aquesta tierra,

135 por activa y por pasiva, una oración imperfecta.

Como es la mina ${ }^{48}$ Manila

de figuras extranjeras,

tiene sombras $y$, por tanto,

140 las figuras embelesan.

Dorsa habentes contra Templum ${ }^{49}$

es el rasgo que campea,

aunque es Fabila ${ }^{50}$ timater $^{51}$

de Ticiano las pavesas.

145 El Comercio de estas Yslas

ya comercia en la pobreza,

y cuantos arbitrios toma

tantos quedan en idea.

Las Provincias desoladas

150 se hallan de continuas guerras

que los Tirones ${ }^{52}$ infieles

48. Quizás diga "mira".

49. Dorsa habentes contra templum [Domini]: "De espaldas al santuario de Yavé". Ezequiel, 8, 16. Traducción: Sagrada Biblia. Versión directa de las lenguas orientales, por Eloíno Nácar Fuster y Alberto Colunga Cueto, OP, novena edición. Madrid 1971.

50. Favila: pavesa, ceniza del fuego, según el DRAE.

51. Podría decir "timates".

52. Antigua denominación para un grupo nativo moro (musulmán) de Mindano. Este pueblo se cita, por ejemplo, en dos folletos publicados por el dominico Fr. Juan de Arechederra, obispo de Nueva Segovia, a mediados del siglo XVIII: Puntual relación de lo acaecido en las 
anualmente nos franquean.

Bisayas $^{53}$ y Camarines,

la Pampanga y Zebú ${ }^{54}$ quedan

155 en varios pueblos quemados

de la moruna fiereza.

La Provincia de Zambales

y el partido están en vela

y no cesan de llorar

160 los cautivos que se llevan.

Estas noticias no son

novedades de gaceta

ni allá del tiempo de Adán,

sino las que hoy nos molestan.

165 Tanta es la copia de Ynfieles ${ }^{55}$

que en esta tierra se encuentra

que no dudo compararlos

al gremio de las Estrellas.

Es tal su inhumanidad,

170 su barbarie y su fiereza

que entonces matan a un hombre

cuando el hombre menos piensa.

Con flechas envenenadas

en los bosques nos esperan,

175 y al transitar descuidados

a la Eternidad nos echan.

Al que matan le despojan

de los hombros la cabeza

y para saciar su sed

180 veven en la calabera.

También comen carne humana

cuando otra cosa no encuentran

y no son escrupulosos

de vever la sangre fresca.

expediciones contra Moros Tirones, Malanaos y Camucones destacadas en los de [1]746 y [17]47 y Continuacion de los progresos, y resultas de las expediciones contra Moros, Tirones y Camucones en este Año de 1748. Con noticia de los principios de las nuevas missiones de los Reynos de lolo, y Mindanao.

53. Visayas.

54. Cebú.

55. Estos "infieles" no son ya los moros, sino los negritos e igorrotes que comentamos en el texto. 
185 Donde los coge la noche allí paran y se acuestan, sin más abrigo ni ropa que ojas de Árbol y unas yerbas.

Con un girón mal tejido,

190 que biene a ser cual coraza, medio tapan el trasero y un tanto la delantera. De ancho tiene cuatro dedos, largo de dos varas completas,

195 con que viene a mal cubrir las partes que son pudendas. No hay en ellos otro ajuar que un cruel arco y varias flechas con que matan a los corzos

200 y a cualquier ave que vuela. Tienen raras propiedades que por malas no se espresan, baste decir que son tales cuales el diablo quisiera ${ }^{56}$.

205 En esta Palestra viven cuantos vienen a esta tierra, donde Dios con sus piedades nos ampara con largueza. Luego pues que aquí llegamos

210 nos dieron la enhorabuena de multiplicanti gentem, con lo demás de la letra. A los tres o cuatro meses repartieron las boletas

215 y cada pobre salió para el lugar de sus penas.

Cuatro fueron hacia el Monte de Tunkín ${ }^{57}$ por sus prendas. Cinco Santos para China y en

220 el Parián ${ }^{58}$ dos de prueba. A Cagayán fueron cuatro y a Pangasinán, la vella,

56. Se refiere a la sodomía.

57. Se corresponde en buena parte con la zona septentrional del actual Vietnam.

58. Antiguo barrio chino de Manila. 
tres, y mi persona noble para llenar la cuarteta.

225 Cada cual en su destino a aprender lengua comienza y quiere Dios que en tres meses todos hablen bien en ella. Los Prelados nos protegen

230 con una suma largueza, de modo que no ahi escusa para cumplir cuanto ordenan. Por tanto todos trabajan con tan singulares fuerzas

235 que se conoce que Dios en nuestro amparo se esmera. Todos estamos dispersos, cada cual con sus ovejas en respectivos lugares

240 que señala la obediencia. No nos faltan pesadumbres, mortificación, ni penas, porque es fruta universal que abunda en todas las tierras.

245 Esto es lo que es para todos y lo que hay puertas afuera, pero hay otras siguidillas acá dentro de las puertas. Basta ya de novedades,

250 que la musa se chisquea y no es justo el molestarla por el resto que aquí resta. Dios le guarde muchos años procurante y no en Judea.

255 Paniqui, tantos del mes en el año de sesenta.

Si te preguntan quién es, diles que un cierto quidán ${ }^{59}$, un vizcaíno medio burro

260 o, si no, que es el Alma en pena.

59. Como hemos comentado en el texto, puede tratarse del kidang, una especie de ciervo enano. 